\title{
POLÍTICAS PÚBLICAS DE FORMAÇÃO PARA O TRABALHO DE PESSOAS COM DEFICIÊNCIA DO GOVERNO DO ESTADO DO PARÁ
}

\author{
PUBLIC TRAINING POLICIES FOR THE WORK OF PEOPLE WITH DISABILITIES FROM \\ THE GOVERNMENT OF THE STATE OF PARÁ
}

\author{
G. P. da SILVA'; I. A. OLIVEIRA²; J. BENJAMIN³, ${ }^{*}$
}

\begin{abstract}
${ }^{1}$ Universidade Federal do Pará (UFPA), Programa de Pós-Graduação em Educação da UFPA, Brasil. Email: gpsilva@ufpa.br 2 Universidade Estadual do Pará (UEPA), Programa de Pós-Graduação em Educação da UEPA/PPGED, Brasil. E-mail: nildeapoluceno@uol.com.br

${ }^{3}$ Universidade Federal do Pará (UFPA), Programa de Pós-Graduação em Educação PPGED/UFPA, Brasil. Email: janetebenjamim@yahoo.com.br
\end{abstract}

\section{ARTICLE INFO \\ Article history: \\ Received 2018-07-12 \\ Accepted 2018-12-20 \\ Available online 2018-12-21}

*Autor correspondente:

E-mail:janetebenjamim@yahoo.com.br
Palavras-chave: Políticas públicas. Formação para o trabalho. Inclusão de deficientes.

Keywords: Public policy. Training for work. Inclusion of the people with disabilities.

RESUMO. O estudo se caracteriza como pesquisa qualitativa exploratória para uma estratégia de estudo de caso. Nos propomos a investigar: onde estão localizados os programas de formação para $o$ trabalho para pessoas com deficiência-PcD do governo do estado do Pará e quais políticas públicas estão sendo realizadas no estado? Objetivo: Levantar e analisar as políticas públicas de formação para o trabalho do governo do estado do Pará, referente às Pessoas com Deficiência, o estudo foi realizado no período de abril a outubro de 2016. Locus: SEDUC/PA, escolas especializadas da SEDUC e SEASTER. Objeto: Programa de formação para o trabalho de PcD do governo do Estado do Pará. Resultados: foram localizadas três escolas especializadas da SEDUC em Belém que possuem programas de formação para o trabalho, assim como, parceria com o sistema " $S$ " e o Centro de Inclusão e Cidadania-CIIC, contradições entre as políticas públicas do governo do estado do Pará/práticas pedagógicas dos professores/discurso da legislação. A teoria das contradições, foram fundamentadas em Marx (1982), com base no materialismo histórico dialético. Conclusão: Podemos constatar uma forte contradição entre as políticas públicas de formação para o trabalho do governo do estado do Pará e as legislações vigentes, visto que, o estado não possui regulamentações específicas para a formação profissional das pessoas com deficiência, incluindo essas pessoas nas cotas de programas oferecidos às pessoas não deficientes.

ABSTRACT. The study is characterized as exploratory qualitative research for a case study strategy. We propose to investigate: where are the training programs for people with disabilities-PwD of the state government of Pará and what public policies are being carried out in the state? Objective: To raise and analyze the public training policies for the work of the government of the State of Pará, regarding People with Disabilities, the study was carried out from April to October 2016. Locus: SEDUC / PA, specialized schools of SEDUC and SEASTER. Purpose: Training program for the work of PwD of the government of the State of Pará. Results: three SEDUC specialized schools in Belém were located that have training programs for the work, as well as a partnership with the "S" system and the Center for Inclusion and Citizenship - CIC, contradictions between the public policies of the state of Pará / teachers' pedagogical practices / discourse of legislation. The theory of contradictions, were based on Marx (1982), based on dialectical historical materialism. Conclusion: We can see a strong contradiction between public training policies for the work of the Pará state government and the current legislation, since the state does not have specific regulations for the professional training of people with disabilities, including those in the quotas programs offered to non-disabled persons. 


\title{
1. Introdução
}

Inclusão no Trabalho de Pessoa com Deficiência $(P c D)$ se tornou comum desde 1994 após a Conferência de Salamanca ocorrida na Espanha, que aprova a Declaração de Salamanca, no Brasil este documento dá suporte à reforma educacional, ocorrida com a LDB № 9394/96, que garante em seus artigos 58, 59 e 60, incisos II e IV a Inclusão Educacional e a terminalidade educacional específica para $\operatorname{PcD}$ e sua efetiva inclusão em programas de formação para o trabalho. A educação inclusiva, faz parte da política da educação especial no Brasil.

A Declaração de Salamanca no artigo 10 do Item III - Orientações para ações em níveis regionais e internacionais, chama a necessidade da criação de programas educacionais para atender a população de jovens e adultos com deficiência.

\begin{abstract}
Existem milhões de adultos com deficiências e sem acesso sequer aos rudimentos de uma educação básica, principalmente nas regiões em desenvolvimento no mundo, justamente porque no passado uma quantidade relativamente pequena de crianças com deficiências obteve acesso à educação. Portanto, um esforço concentrado é requerido no sentido de se promover a alfabetização e o aprendizado da matemática e de habilidades básicas às pessoas portadoras de deficiências através de programas de educação de adultos. Também é importante que se reconheça que mulheres têm frequentemente sido duplamente desavantajadas, com preconceitos sexuais compondo as dificuldades causadas pelas suas deficiências. Mulheres e homens deveriam possuir a mesma influência no delineamento de programas educacionais e as mesmas oportunidades de se beneficiarem de tais. Esforços especiais deveriam ser feitos no sentido de se encorajar a participação de meninas e mulheres com deficiências em programas educacionais (UNESCO, 1998).
\end{abstract}

Essa Declaração, no artigo 53, do Item E - Áreas Prioritárias ressalta a relação entre escola e trabalho.

Jovens com necessidades educacionais especiais deveriam ser auxiliados no sentido de realizarem uma transição efetiva da escola para o trabalho. Escolas deveriam auxiliá-los a se tornarem economicamente ativos e provêlos com as habilidades necessárias ao cotidiano da vida, oferecendo treinamento em habilidades que correspondam às demandas sociais e de comunicação e às expectativas da vida adulta. Isto implica em tecnologias adequadas de treinamento, incluindo experiências diretas em situações da vida real, fora da escola. O currículo para estudantes mais maduros e com necessidades educacionais especiais deveria incluir programas específicos de transição, apoio de entrada para a educação superior sempre que possível e conseqüente treinamento vocacional que os prepare a funcionar independentemente enquanto membros contribuintes em suas comunidades e após o término da escolarização. Tais atividades deveria ser levadas a cabo com o envolvimento ativo de aconselhadores vocacionais, oficinas de trabalho, associações de profissionais, autoridades locais e seus respectivos serviços e agências (UNESCO, 1998). 
A Inclusão no Trabalho de Pessoas com Deficiência se dá como direito a partir das discussões e aprovações em conferências e convenções internacionais, dentre elas a Conferência de Genebra, ocorrida em 1ํ de junho de 1983 e promovida pela Organização Internacional do Trabalho-OIT que aprova a recomendação № 168 que trata da reabilitação profissional e do emprego das $\mathrm{PcD}$ e a Convenção Internacional de Direito das $\mathrm{PcD}$, realizada pela Organização das Nações Unidas-ONU, em 13 de dezembro de 2006, ambas apresentam políticas internacionais de incentivo ao trabalho das $\operatorname{PcD}$ que "envolve providências que vão desde a reserva obrigatória de vagas até incentivos fiscais [...], destinado ao custeio de programas de formação profissional na esfera pública e privada" (BENJAMIN, 2013, p. 66).

A Lei 8213/91 que estabelece as cotas para Inclusão no Trabalho, não é uma lei específica para tal e sim uma lei que estabelece direitos aos beneficiários da Previdência Social de modo geral, apresentando apenas em seu artigo 93 as cotas específicas de inclusão, que reafirma o estabelecido na Lei № 7853/89, que trata da Inclusão no Trabalho das Pessoas com Deficiência.

Vale ressaltar que concebemos Inclusão no Trabalho das PcD como exercício pleno de cidadania, onde as PcD devem sentir-se uteis, unindo necessidade financeira a satisfação humana e não apenas como número que venha gerar benefícios para as empresas se apropriarem de incentivos fiscais que favorecem mais os empresários que os

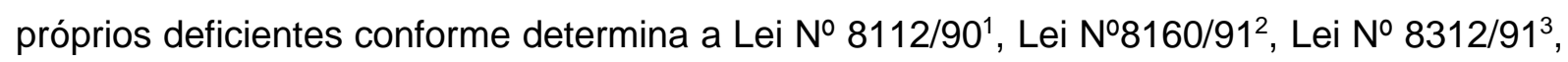
Lei ํo $8742 / 93^{4}$, Lei № $10.172 / 2001^{5}$, Decreto № $129 / 91^{6}$, Decreto № $2536 / 98^{7}$ e Decreto № $3298 / 99^{8}$.

Durante o período de estudos do mestrado, constatamos que a lei ำ $8213 / 91$ que determina as cotas de inclusão em empresas (trabalho formal), não exige formação para o trabalho e muito menos escolaridade. Observamos, também, que as empresas privadas são bonificadas pelo Estado ao receberem isenção fiscal por incluírem $\operatorname{PcD}$ ou readaptadas. Benjamin (2013, p.68 ao citar BIANCHETTI, 2011), diz que:

é considerado politicamente correto e economicamente vantajoso para quem inclui, pois a lei de cotas brasileira se constitui de fortes benefícios às empresas privadas que se beneficiam de isenção de impostos por incluírem marginalmente as PcD alegando falta de formação para o trabalho.

${ }^{1}$ Dispõe sobre o Regime Jurídico dos Servidores Públicos Civis da União, das Autarquias e das Fundações Públicas Federais.

2 Dispõe sobre a caracterização de símbolo que permita a identificação de pessoas portadoras de deficiência auditiva.

${ }^{3}$ Dispõe sobre os planos de benefícios da previdência social;

${ }^{4}$ Dispõe sobre a organização da Assistência Social;

${ }^{5}$ Lei № 10.172/2001 Aprova o Plano Nacional de Educação.

${ }^{6}$ Promulga a Convenção no 159 , da Organização Internacional do Trabalho - OIT, sobre Reabilitação Profissional e Emprego de Pessoas Deficientes.

${ }^{7}$ Dispõe sobre a concessão do Certificado de Entidade de Fins Filantrópicos.

${ }^{8}$ Dispõe sobre a Política Nacional para a Integração da Pessoa com Deficiência. 
Mediante o exposto, propomos investigar: quais políticas públicas estão sendo realizadas no estado do Pará, direcionadas para formação profissional de PcD?

O Objetivo deste estudo é levantar e analisar o Programa de formação para o trabalho de $\mathrm{PcD}$ que faz parte das políticas públicas de formação para o trabalho do governo do estado do Pará.

Apresentamos os resultados parciais da pesquisa exploratória realizada no período de abril a outubro de 2016, na Secretaria de Estado de Educação do Pará (SEDUC) e em escolas especializadas da SEDUC e Secretaria de Estado de Assistência Social Trabalho Emprego e Renda-SEASTER.

\section{Fundamentação}

Os Referenciais Teórico-Metodológicos deste estudo são Lüdke e André, (1986), Chizzotti (2010) e Marconi e Lakatos (2011), entre outros. O corpus da pesquisa tem por base a abordagem teórica do materialismo histórico dialético de Marx e Engels (NETO, 2011).

Na perspectiva histórico-dialética a pesquisa apresenta:

Um caráter conflitivo, dinâmico e histórico da realidade. Sua postura marcadamente crítica expressa a pretensão de desvendar, mais que o "conflito das interpretações", o conflito dos interesses. Essas pesquisas manifestam um "interesse transformador" das situações ou fenômenos estudados, resgatando sua dimensão sempre histórica e desvendando suas possibilidades de mudança (GAMBOA; SANTOS, 1994, p. 97).

O método em Marx (NETO, 2011), busca no objeto o movimento da história e suas contradições, o que faz com que o pesquisador parta da aparência para essência do fenômeno estudado. Para Marx, as categorias são históricas e transitórias. Neste sentido, a categoria deficiência, utilizada neste estudo, inicia seu marco histórico envolvendo pessoas excluídas socialmente de exercer quaisquer atividades produtivas, o que nos torna pesquisadores incomodados, pelo fato de nos confrontar com uma sociedade que exclui dezenas de trabalhadores em plena crise do trabalho.

Na perspectiva histórica-dialética de Marx, o conhecimento teórico do objeto remete - pesquisador a realidade concreta que não deixa de ser a síntese de muitas determinações. Oliveira (1993) destaca que Marx introduz as categorias de "história" e "dialética", explicitando um relativismo presente na questão referente ao determinismo econômico. Explica que em Marx, a relação-recíproca passa a ser o instrumento fundamental de análise e o ponto de referência para a determinação e somente o método dialético-histórico permite a compreensão dos fatos passados em função dos fatos atuais, por estes se constituírem numa "síntese das determinações". 
Desta forma, no pensamento de Marx, é a partir dos fatos concretos que se elabora a análise dos fatos para chegar ao concreto pensado, à síntese das determinações, à unidade do diverso. O caráter objetivo e empírico do conhecimento científico está presente em Marx.

O movimento histórico da deficiência no Pará, no Brasil e no mundo vem se relacionando com múltiplas situações que ora são exigidas escolaridade para inclusão no trabalho, ora não precisa de formação e escolaridade, que faz com que a classe dominante, que toma conta dos meios de produção capitalista, inclua marginalmente ou exclua os deficientes do mercado de trabalho, à medida que os inclui em trabalhos manuais, de baixa renda, alegando não haver meios de inseri-los em outras atividades, de melhor situação financeira, por não terem formação específica para ocuparem outros cargos.

Os autores que nos propomos a discutir as categorias de análise, tratam de conceitos que estarão esclarecendo o objeto em estudo, pois "a teoria é, para Marx, a reprodução ideal do movimento real do objeto pelo sujeito que pesquisa: pela teoria, o sujeito reproduz em seu pensamento a estrutura e a dinâmica do objeto que pesquisa" (NETO, 2011, p. 21).

As contradições encontradas no estudo estão sendo fundamentadas nos princípios da dialética de Marx e uma de suas categorias teóricas utilizadas no estudo é a práxis. Ao expor as teses sobre Feuerbach, Marx (1982, p. 12) afirma, na tese II, que:

a questão de saber se cabe ao pensamento humano uma verdade objetiva não é uma questão teórica, mas prática. É na práxis que o homem deve demostrar a verdade, isto é, a realidade e o poder, o caráter terreno do seu pensamento. A disputa sobre a realidade ou não-realidade do pensamento isolado da práxis - é uma questão puramente escolástica.

Na tese III ao falar da doutrina materialista sobre a alteração das circunstancias e da educação, Marx (1982) explica que o educador deve ser educado a entender que as circunstancias são alteradas pelos homens e por isso separa a sociedade em duas partes, uma colocada acima da sociedade, a qual só pode ser modificada com atividade humana ou alteração de si próprio e que só pode ser apreendida e compreendida racionalmente como práxis revolucionária.

Partindo desse princípio, concebemos o objeto desse estudo como parte da superestrutura da sociedade paraense, aonde os programas de formação para o trabalho destinados às $\mathrm{PcD}$ são políticas que vão além da sociedade que vive do trabalho e que o capital está diretamente influenciado pela legislação do Estado e influenciando nessa modificação da legislação, da formação do capital humano e transformação no mundo do trabalho pelo enfraquecimento do Estado, retirada dos direitos sociais e fortalecimento do capital pela modificação do estado do bem estar social.

O movimento da história no processo de produção capitalista fez com que os programas de formação sofressem modificações constantes, de forma que esses se 
adequassem conforme as exigências do capital e na contra - mão da práxis revolucionária dos trabalhadores da educação.

Desta forma, o estudo passa a ser conduzido, partindo do materialismo histórico dialético, acompanhando o movimento dialético da história.

\section{Metodologia}

Optamos por fazer uma pesquisa qualitativa e um estudo de caso. Na pesquisa de abordagem qualitativa a "obtenção de dados descritivos obtidos no contato direto do pesquisador com a situação estudada, enfatiza mais o processo do que o produto e se preocupa em retratar a perspectiva dos participantes" (LUDKE; ANDRÉ, 1986, p. 13). Para as autoras, as estratégias metodológicas do Estudo de Caso possibilitam: a descoberta, a "interpretação em contexto", buscando retratar a realidade de forma completa e profunda, por meio do uso de uma variedade de fontes de informação; revela experiências vicária e permite generalizações naturalísticas. Além disso, procura representar os diferentes e conflitantes pontos de vista presentes numa situação social. (LUDKE; ANDRÉ, 1986).

Chizzotti (2010) nos orienta à uma caracterização abrangente de um caso com a finalidade de organizar um relatório ordenado e crítico de uma experiência, ou avalia-la analiticamente. Segundo o autor, o desenvolvimento de um estudo de caso supõe três fases: seleção e delimitação do caso, trabalho de campo e organização e redação do relatório.

Neste estudo seguiremos as seguintes estratégias metodológicas: levantamento bibliográfico, levantamento documental, mediante análise da legislação a respeito do assunto e de documentos fornecidos pelas Instituições, entre os quais o plano de trabalho, assim como projetos extras desenvolvidos pelo programa; realização de entrevistas semiestruturadas com coordenadores dos programas de formação, responsáveis de alunos, bem como com alunos matriculados nas escolas estaduais pesquisadas. A observação é de grande relevância para o cruzamento dos dados levantados no desenvolvimento da pesquisa. $\mathrm{Na}$ análise dos dados foi utilizada a técnica de categorização, que se apresenta como uma:

ação de organização lógica dos dados coletados, viabilizando uma estrutura organizadamente integrada. A partir das categorias de análises construídas é possível ao pesquisador refletir criticamente sobre a análise das informações obtidas na investigação (OLIVEIRA, MOTA NETO, 2011, p.163).

Neste artigo estão sendo apresentados os dados levantados na pesquisa exploratória realizada no período de abril a setembro de 2016. 


\section{Resultados e discussões}

$\mathrm{Na}$ pesquisa exploratória tivemos a oportunidade de ouvir num primeiro momento o desabafo dos profissionais que desenvolvem os programas e a inquietação em que estes sujeitos se encontram, estabelecemos contatos, coletamos documentos e selecionamos possíveis sujeitos a serem estudados.

Identificamos que tanto o Centro de Inclusão e Cidadania-CIIC/Sistema Nacional de Emprego-SINE, quanto a Coordenadoria de Educação Especial-COEES/SEDUC, as escolas especializadas da SEDUC e as filantrópicas conveniadas com a SEDUC possuem um programa específico de colocação no mercado de trabalho e acompanhamento em serviço.

Na SEDUC existem três escolas especializadas em Belém que possuem programas de formação para o trabalho em parceria com o sistema "S" com formação para o trabalho. Solicitamos o Projeto Político Pedagógico-PPP destes Programas, mas não tivemos ainda acesso para análise.

Observamos em lócus o espaço físico e identificamos os profissionais lotados pelo governo do estado para realização e execução das oficinas de panificação, jardinagem, tapeçaria, artesanato, informática e arte culinária.

Segundo os informantes das escolas, as oficinas mais específicas para o mercado de trabalho na área da indústria e do comércio, os alunos são encaminhados ao SENAI/SENAC. Além das escolas especializadas da rede estadual, constatamos também o sistema de parceria das escolas especializadas privadas e filantrópicas (LDB № 9394/96), que possuem programas próprios e parceria com sistema "S", cujo profissionais se mantem lotados pela SEDUC com a finalidade de realizar os programas de atendimento destinado a formação para o trabalho.

Identificamos, também, algumas contradições entre o que o governo do estado do Pará propõe às pessoas com deficiência e as práticas pedagógicas dos professores nos programas e o discurso da legislação. nos cabe daqui em diante aprofundamento e análise, no sentido de confirmar se os programas atendem aos discursos das legislações vigentes e quais políticas públicas executadas aos deficientes nos programas de formação para o trabalho.

As principais contradições encontradas até o presente momento com a pesquisa exploratória, análise documental e legal, foram as seguintes:

1) a terminalidade apresentada na legislação (LDB № 9394/96 e a Resolução № 02/2001) exige inclusão em programas específicos de formação para o trabalho ou no mercado de trabalho, mas o que constatamos na pesquisa exploratória é que a SEDUC 
até o presente momento não possui nada regulamentado a respeito da terminalidade específica para deficientes;

2) a Lei № 8213/91 que favorece a inclusão no trabalho de PcD não exige escolaridade e nem formação específica para inclusão no trabalho de $\mathrm{PcD}$, porém as empresas apresentam o perfil de profissional para ocupar as vagas e neste perfil está presente a escolaridade e a formação para o cargo. O que evidencia fator dificuldade na acessibilidade da pessoa com deficiência no mercado de trabalho.

Neste estudo, destacamos a necessidade do sujeito deficiente ser protagonista de sua história e da deficiência no Brasil e em especial no estado do Pará (lócus da pesquisa). Entretanto, as leis produzidas são contraditórias às políticas públicas aplicadas aos deficientes, bem como em relação as falas dos sujeitos deficientes, pais de alunos, gestores da COEES/SEDUC e profissionais que fazem os programas de formação.

As legislações que se referem aos sujeitos deficientes, surgem com o significado histórico e ideológico de assegurar os direitos dos deficientes na sociedade, porém em cada momento da história e de acordo com os acontecimentos nacionais e internacionais, estas aparecem com interesses particulares implícitos que ora favorecem as PcDs, ora beneficiam o sistema de produção capitalista, que surgem como base de sustentação mercantil para escolas, hospitais e centros de habilitação e reabilitação privada e empresas que empregam em precárias condições.

Constatamos, também, que grande parte do aluno da Educação Especial, encontram-se fora do mercado de trabalho devido não fazerem parte do perfil das empresas empregadoras e atualmente devido a flexibilidade do trabalho, onde as empresas ao demitir os profissionais não deficientes, reduzem o número de deficientes conforme as cotas exigidas na lei de cotas. Além disso, a lei №8213/91, que estabelece as cotas de Inclusão, estipula um percentual de $2 \%$ a $5 \%$, de acordo com o número de trabalhadores das empresas para inclusão de PcD no trabalho, assim como o artigo 59 da LDB № 9394/96 regulamenta a terminalidade escolar das PcD e o encaminhamento a programas de formação para o trabalho.

Identificamos ainda as seguintes situações:

1) "exigência" por parte das empresas empregadoras de formação para o trabalho das PcD incluídas nas cotas, o que as empresas denominam de "perfil profissional";

2) Justificativa das empresas ao demitir cotistas com limitações (PcD) de que estes não possuem escolaridade/formação para o cargo;

3) A maioria das PcD incluídas nas cotas das empresas, queixam-se de serviços muito pesados, pois a falta de escolaridade e formação para outras funções faz com que estes sejam incluídos em trabalhos braçais. 
Desta forma, é contraditório falar de inclusão no trabalho para PcD quando encontramos um número bem elevado de pessoas não deficientes fora do mercado de trabalho e que buscam formação constante como forma de ter mais possibilidade de conquistar vagas.

O conceito de capital humano, a partir da análise de Gaudêncio Frigotto constitui o construtor básico da economia da educação, no bojo das discussões a respeito dos fatores explicativos do crescimento econômico. Segundo o autor: "a preocupação básica ao nível macroeconômico é, então, a análise dos nexos entre os avanços educacionais e o desenvolvimento econômico de um país" (FRIGOTTO, 2010, p. 49-50).

Neste sentido, a educação consiste no principal capital humano e é concebida como potenciadora do fator trabalho, tornando-se um investimento como outro qualquer (FRIGOTTO, 2010). Para o autor, a educação como teoria do capital humano, como fator primordial do desenvolvimento econômico, consiste em uma ferramenta determinante para se investir em melhorias da renda individual e familiar, porém, torna-se um forte indutor para o crescimento da mercantilização da educação.

O que se percebe é que o crescimento de matriculas na rede privada de ensino a partir da década de 1990, segundo pesquisas voltadas para essa área, é bem significativo, principalmente em nível superior, no qual os profissionais buscam melhorar a qualidade de sua mão de obra e se tornarem mais atraentes para o mercado do trabalho. A concorrência em busca de melhores empregos e salários é desumana, o desemprego estrutural cresce assustadoramente e as profissões tornam-se obsoletas, a luta constante por novas formações e atualização por aqueles que desejam permanência em cargos ocupados em empresas multinacionais torna-se um tanto quanto selvagem a ponto de se tornar desumano. A robótica e as tecnologias de informação tornam-se prioridades, e com isso, ocorre o enfraquecimento das lutas pelos trabalhadores via sindicatos, que chegam a fazer com que os trabalhadores se sintam na necessidade de aceitar postos de trabalho com menores salários que não sejam das profissões e cargos anteriormente ocupados.

Mesmo com a lei de cotas, que "facilita" o processo de inclusão no trabalho de PcD, ainda é perceptível a exclusão por falta de políticas públicas de formação humana para o trabalho das PcD.

Dentre os achados mais recentes, detectamos que as políticas públicas de formação para o trabalho do governo do estado do Pará estão localizadas de forma bem polarizada, tais como:

1. Os $5 \%$ das reservas de vagas nos cursos técnicos profissionalizantes das Escolas Técnicas Estaduais-EETEPAs, conforme determina o decreto № 3298/99, não atendem aos Deficientes intelectuais - DI, porque constatamos que o número de deficientes que ocupam as vagas não são deficientes intelectuais-DI, pois para estes, a possibilidade de escolaridade alcançada ao que exige as escolas técnicas é quase que nula devido 
apresentarem dificuldades em terminar o ensino fundamental, visto que os cursos são concomitantes ou subsequentes ao ensino médio;

2. Em duas Unidades Especializadas da SEDUC, somente uma está privilegiando o aprofundamento do estudo;

3. No sistema "S" os informantes apresentaram dificuldades ae permanência dos Dls devido a pouca escolarização e por não saberem ler os materiais apresentados pelo curso.

Observamos na pratica com os profissionais das escolas especializadas e do SINE, o quanto está sendo difícil conseguir pessoas deficientes que atendam ao que as empresas exigem, pois além da escolaridade, ainda afirmam não estar preparadas para receber determinados tipos de deficiência, como é o caso de pessoas com cegueira. Desta forma, mesmo com a legislação favorável aos deficientes, as empresas colocam barreiras no sentido de excluírem aqueles que não tiveram acesso ao conhecimento escolar ou que não conseguiram alcançar a escolaridade mínima.

Mantoan (2003) explica que a incapacidade de aprender é particularizada e transferida para a pessoa com deficiência. A escola, então, não assume a responsabilidade de lidar com a compreensão das diferenças sociais, por isso, nega não só as pessoas com deficiência, mas todas as minorias que de alguma forma foram lesadas de seus direitos à educação e de estar inserida na sociedade.

Oliveira (2005, p.71) destaca que a política de educação inclusiva "desloca o enfoque individual, centrado no/a aluno/a, para a escola, reconhecendo no seu interior a diversidade das diferenças: individuais, físicas, culturais e sociais". Neste deslocar do enfoque individual para o escolar, ressignifica tanto os sujeitos quanto a sala de aula considerando modificações pedagógicas que possibilite o melhor desenvolvimento dos alunos com deficiências. Isto significa olhar a pessoa com deficiência não pelos seus limites e sim por suas possibilidades de aprendizagem e as possíveis estratégias metodológicas.

Que sentido faz investir em políticas públicas para pessoas que supostamente são consideradas incapazes? É importante ressaltar que o investimento em capital humano às $\mathrm{PcD}$ é tido para alguns governos como fundo perdido, visto que historicamente as PcD são consideradas ineficientes e incapazes.

Mazzotta (1999) afirma que o Brasil passa a oferecer educação ao público da educação especial "somente no final dos anos cinquenta e início da década de sessenta do século XX", o qual se inspira nos modelos Europeus e Estados Unidos da América, com o olhar mais para o ensino profissionalizante.

$\mathrm{Na}$ pesquisa exploratória detectamos que alguns técnicos e professores de escolas especializadas e do AEE são comprometidos com a educação das pessoas com deficiência. A educação é tratada por estes profissionais como formação humana, ou seja, uma 
formação de cidadãos plenos de direitos que valorizem sua força de trabalho e não sejam olhados como mão de obra barata.

Esse comprometimento faz com que, na maioria das vezes, passam a assumir o papel do estado no processo de inclusão no trabalho. Formar cidadãos deficientes plenos para o trabalho torna-se um tanto quanto dispendioso para o estado, pois é muito mais vantajoso encaminhá-los para os cursos profissionalizantes do SENAI e do SENAC, que treinam profissionais para não questionarem o modo de produção capitalista e se conformarem com a exploração capitalista.

Apesar deste comprometimento de alguns profissionais, investir de fato em políticas públicas de formação para o trabalho torna-se uma necessidade, na medida em que, um número significativo de PcD intelectual não conseguiram concluir o ensino fundamental, tornando cômodo para o poder público a não obrigatoriedade do ensino fundamental concomitante ou integrada à educação profissional, pois segundo Araújo (2007) não é permitido em lei alguma vincular educação profissional ao ensino fundamental, sendo necessário que o aluno tenha o mínimo de escolarização para o ensino profissional de nível médio.

Desta forma, é possível que a COEP/SEDUC ofereça cotas as PcD de $5 \%$ das vagas dos cursos profissionalizantes de nível médio nas modalidades subsequentes, concomitantes e integrado nas Escolas de Ensino Técnico do Estado do Pará.

Um fato interessante observado é que segundo a informante da COEP/SEDUC, esta coordenadoria vem oferecendo em seus editais, cotas para $\mathrm{PcD}$, desde 2013 , e só agora foram preenchidas as vagas de alguns cursos, o que pode estar associado à pouca divulgação ou ao fato de que a maioria das $\mathrm{PcD}$ não possui escolarização exigida para o ingresso nos cursos de nível médio profissionalizantes.

\section{Considerações Finais}

Apesar de a escolaridade não ser critério de exigência para que as pessoas com deficiência ocupem os postos de trabalho, no entanto, ao realizarmos pesquisa exploratória para o doutorado, detectamos que as empresas ao procurarem as escolas especializadas e - Sistema Nacional de Emprego-SINE apresentam o perfil de profissional para ocuparem as vagas, limitando assim o ingresso de pessoas que possuem pouca ou nenhuma escolaridade. Com base neste modelo de exigência é cabível apresentar a análise de inclusão exposta por Maciel e Kassar (2011) que se referem as políticas públicas como estivessem em um "terreno de contestação" devido a relação das políticas públicas nacionais e os documentos internacionais não serem assimiladas passivamente nos diferentes países. 
Com isso, observamos na pratica com os profissionais das escolas especializadas $\mathrm{e}$ do SINE, a dificuldade das pessoas deficientes em atender às exigências das empresas, seja de escolaridade ou restrita a certas deficiências. Desta forma, mesmo com a legislação favorável aos deficientes, as empresas colocam barreiras, excluindo aqueles que não tiveram acesso ao conhecimento escolar, não conseguiram alcançar a escolaridade mínima ou por terem alguma deficiência que não seja do interesse dos mesmos.

Observamos que na prática alguns profissionais buscam, por meio de oficinas, desenvolver habilidades de alunos com deficiência, mas a falta de apoio por parte do poder público estadual dificulta em atenderem as exigências das empresas, pois os recursos materiais e de formação, para o desenvolvimento das habilidades para as possíveis competências das PcD encontram-se em precárias condições, conduzindo os profissionais da área ao sucateamento e precariedade no atendimento. Esta situação, apesar dos recursos alternativos e de criatividades por parte dos profissionais, dificulta o trabalho pedagógico de formação para o trabalho com pessoas com deficiências.

A Inclusão Educacional apesar de ser instituída como política pública educacional, não desenvolve de fato e de direito o que se garante em lei. De um lado as leis de inclusão estabelecem uma coisa, as políticas governamentais são aplicadas de outra forma e os profissionais que lidam diretamente com esses alunos realizam na prática pedagógica outra, dificultando a implementação do que de fato deveria ser a proposta da Educação Inclusiva, conforme estabelecido na Declaração de Salamanca de 1994.

Os poucos deficientes que se enquadram nos perfis das empresas são aqueles que por esforços próprios e/ou com a colaboração dos profissionais das escolas especializadas e do Atendimento Educacional Especializado-AEE, conseguiram superar tanto as dificuldades causadas pelas deficiências quanto as dificuldades causadas pelo sistema de ensino.

Os empresários da educação vêm a educação como mercadoria e isso faz com que as empresas exijam os perfis de trabalhadores que possam contribuir com o modo de produção capitalista. Com isto, torna-se cada vez mais evidente na educação a procura por cursos técnicos profissionalizantes e cada vez mais concorridos os cursos universitários voltados para área industrial, principalmente aqueles da área da tecnologias e engenharias.

Formar cidadãos deficientes plenos para o trabalho torna-se um tanto quanto dispendioso para o estado, pois é muito mais vantajoso encaminhá-los para os cursos profissionalizantes do SENAI e do SENAC, que treinam profissionais para não questionarem o modo de produção capitalista e se conformarem com a exploração capitalista.

Segundo os informantes das escolas especializadas da SEDUC, as empresas que mais tem procurado deficientes para incluir no trabalho são as voltadas para o comercio, em especial as redes de supermercado, porém os alunos almejam outras funções e que em alguns casos chegam a recusar as vagas oferecidas, isso evidencia que os alunos com deficiência necessitam de programas de formação não somente para o ensino médio, mais também para o ensino fundamental, onde se encontra a maior demanda da Educação Especial. 
Referências

ARAUJO, Ronaldo Marcos de Lima; RODRIGUES, Doriedson S.(Org.). A pesquisa em trabalho, educação e políticas educacionais - Campinas, SP: Alinea 2012.

BAKHTIN, Mikhail Mikhailovitch. Marxismo e filosofia da linguagem: problemas fundamentais do método sociológico da linguagem - São Paulo: Hucitec, 2012.

BENJAMIN, Janete. Inclusão no trabalho de pessoas com deficiência: um estudo da APAE de Barcarena-PA. Dissertação (Mestrado em Educação) Universidade Federal do Pará. Belém-PA: UFPA, 2013.

BIANCHETTE, Lucídio. In/Exclusão no trabalho e na educação: Aspectos mitológicos, históricos e conceituais-Campinas-SP: Papirus, 2011.

BRASIL. Lei no 9394 de 06 de dezembro de 1996. Disponível em planalto.gov.br. Acesso em 16 de janeiro de 2017.

Lei no 8213 de 24 de julho de 1991. Disponível em planalto.gov.br. Acesso em 16 de janeiro de 2017.

Resolução no 02 de 11 de setembro de 2001. Disponível em planalto.gov.br. Acesso em 16 de janeiro de 2017.

CHIZZOTTI, Antonio. Pesquisa em ciências humanas e sociais - São Paulo: Cortez, 2010.

FRIGOTTO, Gaudêncio. A produtividade da escola improdutiva: um (re)exame das relações entre a educação e estrutura econômico-social capitalista - São Paulo: Cortez, 2010.

GAMBOA, Sílvio Sanchez. SANTOS FILHO, José Camilo dos. Pesquisa Educacional: quantidade-qualidade, 1 ed. São Paulo: Cortez, 1994.

MACIEL, Carina Elizabeth; KASSAR, Monica de Carvalho Magalhães. Políticas Sociais, políticas de inclusão? In: KASSAR, Monica de Carvalho Magalhães (org.). Diálogos com a diversidade: sentidos da inclusão -Campinas-SP: Mercado de Letras, 2011.

MANTOAN, Maria Teresa. Inclusão escolar: o que é? Por quê? Como fazer?. São Paulo: Moderna, 2003.

MAZZOTTA, Marcos José Silveira. Educação Especial no Brasil: História e políticas públicas - São Paulo: Cortez, 1999.

OLIVEIRA, Ivanilde Apoluceno de; MOTA NETO, J. C. A construção de categorias de análise na pesquisa em educação. In: MARCONDES, Maria Inês; OLIVEIRA, Ivanilde Apoluceno de; TEIXEIRA, Elizabeth. (Org.). Abordagens Teóricas e Construções Metodológicas na Pesquisa em Educação. Belém: EDUEPA, 2011, v. 1, p. 167-186.

Saberes, imaginários e representações na construção do saber-fazer educativo de professores/as da educação especial. 2 ed. Petrópolis: RJ: Vozes, 2005.

Reflexões sobre o método dialético de Marx e a sua contribuição para a educação popular. João Pessoa: UFPB, 1993 (mimeo).

KUENZZER, Acácia Zeneida. Pedagogia da Fábrica - São Paulo: Cortez, 2011.

LÜDKE, Menga; ANDRÉ, Marli E.D.A. Pesquisa em educação: Abordagens qualitativas São Paulo: EPU, 1986.

MARCONI, Marina de Andrade; LAKATOS, Eva Maria. Técnicas de pesquisa: Planejamento e execução de pesquisa, amostragens e técnicas de pesquisa, elaboração, análise e interpretação de dados- São Paulo: Atlas, 2011.

NETO, José Paulo. Introdução ao estudo do método de Marx - São Paulo: Expressão Popular, 2011.

UNESCO, Declaração de Salamanca sobre os princípios, política e prática em educação especial. In Biblioteca Virtual de Direitos Humanos. São Paulo: USP. 16/11/1998. 